\title{
Co-evolutionary design concept for urban sustainability based on 'Regenerative' design principles: a case study in Salford, United King- dom
}

\author{
E. Dineth J. Perera*
}

Town Planner, Ministry of Megapolis and Western Development

\begin{abstract}
The absence of a clear definition for sustainability in urban development has brought into defining a comprehensive sustainable concept based on urban design practices. The positive sustainable design practices aim at reducing the damage caused by excessive resource use, or less damage to the environment. Meanwhile, the concept of regenerative design has developed to offer true sustainable practice for transition towards a truly sustainable worldview. The purpose of the research is to investigate how and in which ways regenerative design could be applied to define the sustainability in urban design practices. With that, the regenerative design process was adapted for urban design context through integrated and centralised approach. The ultimate regenerative design process, through the research study, articulates which aspect (method/technology/design) is appropriate for each place, what kind of people for, what yield within the frame of co-evolution of the whole system. Especially, the comparative analysis proved the need of why sustainable design should practice in urban design and at what time and in which ways it should be integrated in to the design process. The radically transformed thinking patterns of practicing sustainable design in the urban planning and urban design, creates sustainable living system, which is mutually integrated with humans and the natural environment.
\end{abstract}

Keywords: Regenerative design, Sustainability, Ecological design, Evolving process

\section{Introduction}

Sustainable design as a current best practice in the built environment which is primarily a neutral prescription addressing to reduce environmental damage while seeking improved overall efficiency. Most of the current sustainable urban design practices aims at utopian sociocultural and environment habitat. Reed (2007, pg674) suggests that "instead of doing less damage to environment, it is necessary to learn how one can participate with the environment by using the health of ecological system as a basis for design". That is creating a platform of need to rethink the sustainable approach, which currently practicing in order to sustain the whole natural living system.

Meanwhile, the concept of regenerative design is developing to offer true sustainable practice for transition of sustainable worldview. It has an ecological approach which is aiming towards the restorative, re-conciliative and regenerative solutions in order to sustain the whole natural living system.

\section{Literature discussion}

2.1. Key sustainable design approaches in urban design

DSince 1972 United Nations' Stockholm Conference setup the debate around environment friendly development which called sustainable development. The Brundtland Commission on Environment and Development (WCED, 1987) tried to define sustainable development but this a vague definition of border thinking perspective.

"Sustainable development is development that meets the needs of present generation without compromising the ability of future generations to meet their needs and aspirations."

However, it gave a birth to thinking about the conflict between human interventions and natural system protection due to rapid urbanisation. This was further developed at the Earth Summit in Rio de Janeiro, Brazil, 1992 through the Agenda 21 Principles and by special consideration of climate change, plus how to respond and adapt to it. Habitat II (UNCHS, 1996) made an extension of Agenda 21 for the provision of sustainable human

\footnotetext{
*Corresponding Author: 
habitats and the main aspects of goals of sustainable human settlements in an urbanizing world that aims at,

“...efficient use of resources; equal opportunities for a healthy, safe and productive life in harmony with nature; and their cultural heritage, spiritual and cultural values; ensures economic and social development and environmental protection...".

It explains the three pillars of sustainable development (Environmental, Economic and Social) as addressed to urban issues in a defined sustainability framework.

This literature derives modern characteristics and principals of; urban planning and architectural principles of sustainable urbanism and concept of compact city, green design, shared space, sustainable transportation system, mixed use neighbourhood, inclusive design, integrated development planning and local selfdetermination.

These principles and concepts of sustainable design became a defensible marketing instrument in a rapid and highly populating urban environment. The high-tech modern world has been highly influenced towards utopian settlement patterns in most of the rapidly developing nations. On the other hand, European countries are moving towards so called "green urbanism" (Beatley, 2004) in the contemporary era. Now European nations realise the importance of sustainable design in urban planning. Indeed, they also had utopian urban models which it can be argued support and encourage more resource consumption without really thinking of future sustainability. As a result of high depletion of resources with ruined environment, and understanding of power and worth of nature, the Europe nations came to the front by thinking of more sustainable solutions within the contemporary urbanisation paradigm.

As such many nations now look upon their development pattern and how 'sustainable' philosophy has been missapplied in designing artificial human settlements instead of vibrant and living communities. Thus, it is addressing hidden objective of implementing economic directives while it uses as marketing tool through great 'sustainable' products?

With all these arguments, ideas and observations, Williams (2007:16) explain green design,

"Sustainable design differs from green design in that it is additive and inclusive it includes continuing, surviving, thriving, and adapting."

Green urbanism is followed by a brand of so called 'green' design and green design becomes the core and fundamental object of green urbanism and urban ecodesign. Birkeland (2002:26-28) explains that ecological design would be "problematic, as design should be fluid, adaptive and self-generating way of thinking... Responsible...Synergistic...Contextual... Restorative... Eco-efficient... Creative... [and] Multi-dimensional [process]." Eco-efficiency (product, process or service design that minimises energy, resources and waste) is a core driver in green urbanism as a model of sustainability.

Cradle-to-cradle design has also been described as a business strategy that generates ecological and social, as well as economic prosperity. The cradle-to-cradle concept views population growth as a benefit not a burden, because of the opportunity for cradle-to-cradle consumption. A cradle-to-cradle approach to design aims to restore the health of living system and the idea of waste being equal to food is a regenerative approach. It eliminates the idea of waste by proposing that waste can equal food. Products and building components should be 100 per cent biodegradable or 100 per cent recyclable to avoid cross-contamination of the waste and resource streams. This moves from a paradigm of cradle-to-grave, which is a linear use of resource resulting in waste, to one with a cyclic use of resource eliminated waste. The cradle-to-cradle future of industry is seen to be a 'world of abundance' rather than one of limits. (McDonough and Braungart, 2002, 2009).

The sustainable design concepts as explored above are good approaches for human settlement development. However, it leads to the question; is it really sustaining our world habitat? If it is then, why still the wold unsustainable and increasing the volume of urban, social, political and environmental issues?

This has arisen because of profit maximization and a market-oriented development pattern. Therefore, the contemporary urbanisation paradigm created more urban sustainability dilemmas, most use sustainability in a way of "coat of diamonds with a sick body". From another perspective the common sustainability behaviour is based on nostalgic, culturally specific and ideology-based notions that change the natural pattern to an artificial human centred model. It is, how humans like to the world to work, not on how it really works. Because of a common or one size of solution trying to fit to the complex system this definition of sustainable development creates only a space for less bad initiatives for a better future rather than a truly sustainable future.

\subsection{Regenerative sustainability - co-evolution of the whole system}

Regenerative design philosophies discuss how humans are part of the nature and without being part of it is unsustainable. The argument is that if humans are part of the nature, then they should follow the 'rules of nature'. These rules have been defined by Barry Commoner as the four laws of ecology: "Everything is connected to everything else; everything has to go somewhere; there is 
no such thing as a free lunch; and Nature knows best" (quoted in Ross, 1991:3).

According to the latest and well reputed definition was introduces by Mang and Reed (2012) as,

Regenerative Development: a system of technologies and strategies for generating the patterned whole system understanding of a place, and developing the strategic systemic thinking capacities, and the stakeholder ngagement/commitment required to ensure regenerative design processes to achieve maximum systemic leverage and support, that is self-organizing and self-evolving.

According to the Krone's original terms, Mang and Reed explain the regenerative design and its essence as,

"Every living system engages in different levels of work, all of which are essential to the system's continuing vitality, viability and capacity for evolution. The lower levels of work focus on current existence of the system itself, either improving the efficiency of its performance, or maintaining the effectiveness of its resources. Only the upper levels improve and regenerate, allow for engagement with potential and with new sources of life and creativity by asking what is the system's unique role in advancing the whole."

Reed (2007:677) suggests a sustainable design base on the idea of whole or living-systems thinking and he proposes the trajectory of whole thinking approach:

'restorative approaches that "restore the capacity of local natural systems to a healthy state of self-organisation"

'reconciliatory approaches which acknowledge "that humans are an integral part of self-organisation"

'regenerative approach' that engage and focus "on the evolution of the whole of the system of which we are part".

Regenerative development acknowledges humans, as well as their developments, social structures and cultural concerns, as an inherent and indivisible part of ecosystems. It sees human development as a means to create optimum health in ecosystems. Understanding the unique and diverse human and non-human elements of each place is a crucial part of regenerative development (Cole et al, 2006; Reed, 2007a.

\subsection{Design as an Integrative Transformational Methodology}

The regenerative design methodology was derived through analysing the application of contemporary sustainable designs, in the areas of complex adaptive systems, emergent properties, resilience, adaptive capacity, heterogeneity, diversity, synergies, constant change, scale:pattern:process:design relationships, multiscale networks, and the constant exchange of materials and energy between and within the living systems. The regenerative design methodology as status as more complex stage, that could integrate of all methodologies result in a regenerative process to create whole, thriving, and healthy living systems. It is interesting that ecological and sustainable theory and knowledge be integrated with design to understand the complex, health and natural principals.

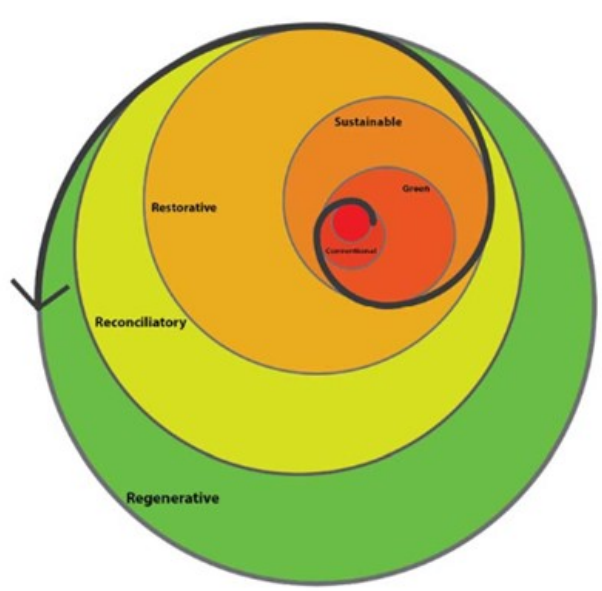

Figure 1: Complex spectrum for integrated approach of achieving regenerative targets

So as an integrated approach, regenerative design methodology re-structured as follows.

1. Understanding of human aspiration

2. Experience and study master pattern of the place

3. Design framework and guidance (Integrated design):

4. Coevolve with the whole system through feedforward interaction

\section{Construction\& Procurement}

\section{Evaluating the Regenerative design principals in Urban Design - Case study review}

Greengate is the historic core of Salford due to its historic value link and evolutionary industrialised economic paradigm. It has diluted his identity and value of place. As such it leads to regeneration process with existing needs. Greengate is located north-west of England, Greater Manchester and east boarder of the Salford city council bounds, just adjacent to the Manchester city centre. The Greengate is known as a gateway to Manchester city centre. The development site bounds with, at the north, Trinity Way and faces the recently constructed Abito apartments at the south side. The West side of the Green gate is bounded by Collier Street, facing the listed former Collier Street and Bath building, Queen Street at the south, and Gravel Lane in east side of the site.

White's winning proposal for the Salford House for Life competition was landscape led and community place- 


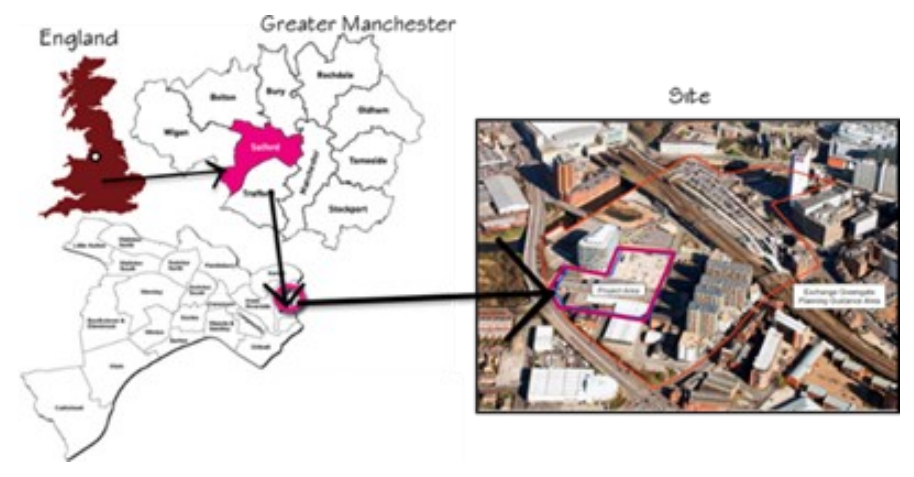

Figure 2: Location map of the Project area

Source: www.salford.gov.uk

making concept design. The overall proposals demonstrate Scandinavian and sustainable place marking characteristics. The main character in the design is providing ownership of the shared amenities that they proposed. There are no private defendable spaces outside the building line.

With the requirement of family housing development in Greengate, the White Arkitekter2 prepared a housing design for the Greengate area. It was the winning design of 'house4life design competition' Greengate. The quality and the sustainable approach that they have followed, the green and sustainable concepts and socioecological improvements, brought on to select the Arkitekter2's Green Gate housing proposal as the case study for this research and to further explore the how it has been used regenerative aspects as a sustainable approach that could be developed to derived process.

3.1. Test the derived regenerative design process with urban housing context (Case Study: White Arkiteks designed the Greengate family housing scheme as a sustainable design approach)

Understanding of human aspiration, the understanding of people who live in and around the site itself is critical and time costly. Ideally the designers or planners should live in the area for a reasonable time period to fully understand the place in social terms.

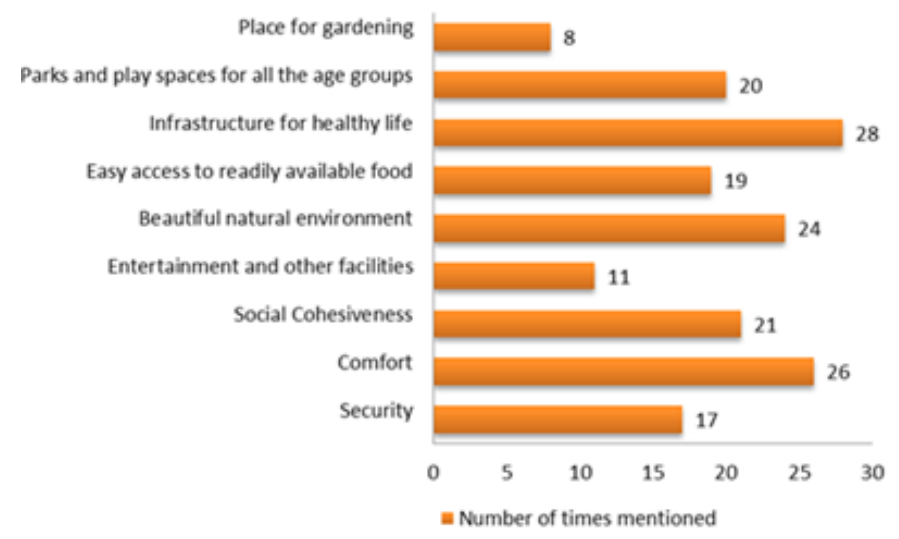

Figure 3: Assessment of design elements used in design, relates to regenerative design principals
According to the analysis of data illustrates in figure 3, the Arkitekter2's design proposal was addressed more sustainable principals in ecological and social perspectives. In majority of them were focused on social needs. Therefore, it is arguable that it had been more bias towards social needs rather than balancing coherence of whole system. Following regenerative design steps will further explain comparatively with the design principals and strategies.

Understanding of human aspiration: To understand the peoples' aspirations who live in and around the site itself used semi structured interviews, short discussions and mental mapping techniques to explore. Following results were analysed. This is quite divers as is usually expected and out of these various aspirations the most frequent mentioned (89\%) is readily available food, infrastructure for healthy life pattern, space for relaxing and play for the different age groups, security, place that they can gather and build relation with neighbours (social cohesiveness), beautiful natural environment, and comfortable place. The design itself has mainly concern on relaxation, integrating similar but not identical natural environment, integrating deferent social groups and values.

Experience and study master pattern of the place: As a second step of regenerative design process, understanding and experiencing the master patterns of the place is very important to prepare the design. It is the foundation for the design. Most of urban designs are based on inadequate site analysis or use typical site analysing methods to understand the place. However, analysing or understanding the master pattern through system analysis in sustainable regenerative design provides a strong base for the design. It guides the future design in sustainable direction. System analysis of regenerative design aims at; what is the master patterns that run the whole system, how and what are the lost parts of the life system and socio-cultural system, the weakened points that make the system die or decay, and potential areas that could regenerate to provide natural background for new source of life.

Accessibility and mobility, as a subsystem in the built environment, has a strong influence on urban life. The site itself has good road network with better hierarchical road pattern and is very well connected with most of the surrounding areas. Figure 04 and 05 illustrates the real ground context scenario in the project site.

Salford city council delineated the northern boundary of the Greengate area as vulnerable for future floods (figure 06; third diagram). That is a reminder for the designers to think what kind of a development could harmonise with Greengate.

Other climatic issues are not that much noticeable. However, according to the future predictions of abnormal 

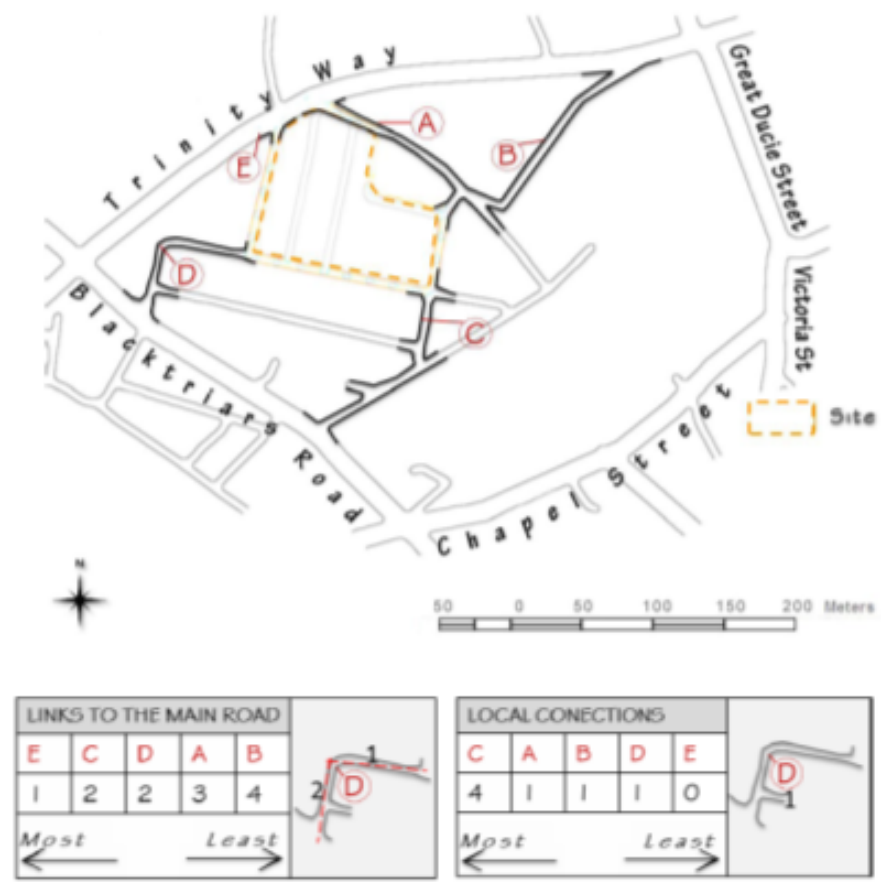

Figure 5: Links to the main roads \& Local connection of the site

fluctuations in temperature, vulnerability for more rain during whole year highlights the importance of adaptability to these kinds of environment changes the potential of benefiting from it too. The figure 06 explains the variations of climatic conditions in a graphical way for Manchester area.

(1)

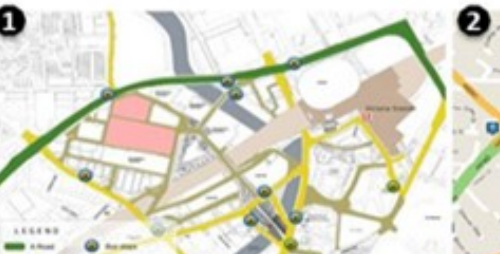

2
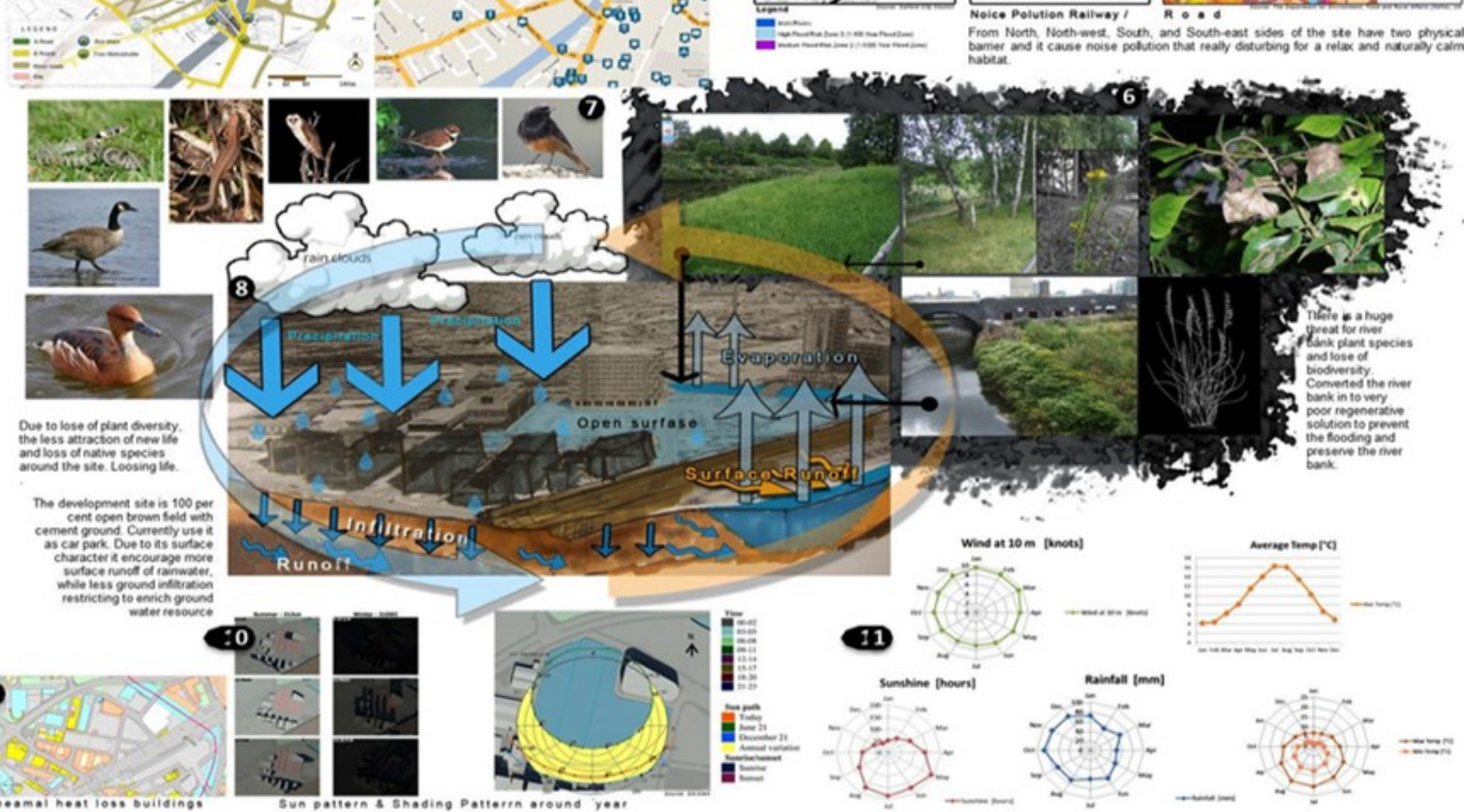

According to the Figure 04; diagram number eight, the natural hydrological system of Greengate has been blocked and its function is not reciprocally benefiting the other sub-systems. It breaks the interaction with plants, animals and humans and even causes vulnerability to flash floods as well.

As per the figure 06 illustration, walkability environment to parks becomes weak. That indicates the need of further green spaces for a more sustainable urban community.

\section{Pedestrian Friendliness \\ Short blocks and lots of intersections are better for walkers.

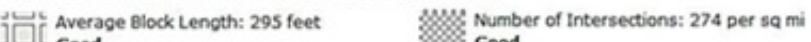

Walkability by Category

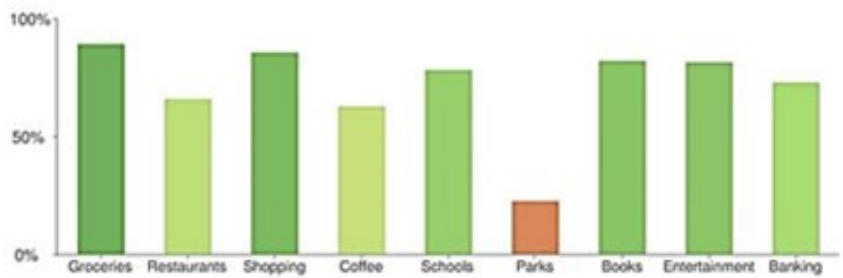

Figure 6: Walkability category

Source: http://www.walkscore.com/

The socio-cultural system of Salford and surrounding of the Greengate area have been positively evolving in the past decades. However, the observation and experience soundly inform, that the social life and behaviour pattern is decaying rapidly which is badly affecting to the British communities' gentle and nature loving society.
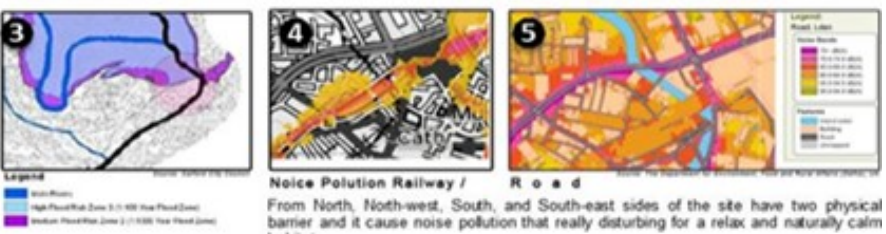

Figure 4: Over role site analysis diagram 
Design framework and guidance (Integrated design): In accordance with in-depth study of the master pattern and human aspirations of the project, leads to formulate design framework with following two main drivers; which are regenerative design principles and integrated strategy formulation. Ultimately, they will provide a guidance to the design development stages of detail, construction and management.

As a whole, the design framework behaves and guides the design, construction and management phases as follows.

a. Revising national and local policies to encourage 'zero waste' products while discouraging environment hazardous products used in urban community

b. Partnerships among local government, private companies and community (e.g. Co-op Shops)

c. Empower the ownership and management of the land for the community

d. Integrate with local green businesses \& green industry

e. Provision of infrastructure to grow organic food for the community

f. 'Local green market' place for buy and sell fresh food (Place for local community to sell their goods and services in competitive with the market)

g. Introduce 'Permaculture' method to grow vegetables, fruit trees, medicinal hubs, pest control vegetation and trees which are local to area

h. Increasing neighbourhood organic food production

i. Encourage pedestrian-and cycling

j. Link range of outside public spaces and amenities

k. Attract animal species by providing habitable environment for them (roof gardening, clean air, warm environment, rich soil cover, etc.)

1. Restore the Irwell river bank

m. Composting toilet waste and organic domestic waste

n. Use passive light and ventilation technology, store and use excess energy for future use

o. Passive Rainwater and Storm-water management

p. Use active renewable energy systems such as photovoltaic (PV) and biomass-fuelled combined heat and power (CHP)

q. Flood resistance settlement design r. Reed beds: Wastewater and sewage from a group of homes is fed into a series of ponds planted with reeds

s. Designing to make historical and current social and ecological processes more visible

t. Ensure that new development respects and protects distinctive landforms, key views, built heritage, water bodies and indigenous plants, animals and ecosystems

u. Use of environmentally sound materials

v. Support and promote internal and external educational programmes that will advance knowledge and understanding on respect and be part of the nature, and maintain the whole habitat, for a selfsustaining society

w. Temporal semi indoor space (Harmony realm) for gather people in extreme cooler and rainy weather conditions

Construction \& procurement: The urban designer's role in achieving regenerative essence in the construction and procurement phase is important. However, it is true enough that the regenerative construction part is specialised and team working with separate professional actors is essential (Butt, Ratnayake, \& Budge, 2016). However, the urban designer as a multidisciplinary professional holds the responsibility of guiding/ directing towards the sustainable path. The important points of construction and procurement phase are explained briefly in the framework of regenerative design.

The construction stage is a more complex and objective process in urban development. On the other hand, it is an accumulation of set of sensitive actions. There are three fundamental aspects to have to be considered in construction stage. First; phased role out with a continuous monitoring process which understands and responds to the co-evolutionary principle is key to regenerative design. In the monitoring process there should be a group with multi-professional interests that represent different fields related to sustainable regeneration such as, ecological engineers and builders, ecological/sustainable urban designers and architects, etc

In the second aspect the construction process should be response and sensitive to the system changes, mainly if it has long construction period. In other words, the constant changes have to be a taken according to the natural, social variations in each construction phase. However, with the limits of cost and resistance to business models of sustainable approaches to development which is difficult to do changes in between. Under the current socio-metabolic regime, Krausmann et al. (2008, p. 652) project by 2050 global energy use and material use will increase by $360 \%$ and $310 \%$, respectively. That will lead to unexpected environment issues on building materials 
and energy flows in all over the earth. Therefore, it is very important and crucial the social groups or individuals should macroscopically decide to do the construction environment and social responsive. If not, that clearly have enormous environmental consequences. It will also require an in-depth knowledge and understanding of the flows of materials, energy and water over time Therefore, community involvement as a final and important aspect, has to identify the changes and needs that whole community need that could be required during the construction process is very important.

All of these aspects of regenerative design process suggest the nature of a mutually beneficial and lifesupporting relationship between built and natural environment, as a core of regenerative and ecological design paradigm. It is the "non-negotiable laws of nature" (Graham, 2003:8).

\section{Coevolve with the whole system through feed-forward}

interaction: After the completion of construction, the product should be transferred to the community with short term and long-term plans, and there has to follow a feed-forward mechanism to coevolve with it as an integral part of nature. In this feed-forward interaction as main connector links the whole evolutionary process. The feed-forward interaction means 'listen \& observe without judging à learn à adapt to the present and change the future socio-economic system by learning not judging'. Reed (2007) suggest to have feed-back approach as "long term aspirations for the project/ community, supports and facilitates the iterative cycles of action, reflection, dialogue as a means of deepening place connections and growing understanding and mutual caring". Referring to his suggestion, in long term ever growing cyclical process tells the requirement of more even practical method than feed-back approach that he suggests. On the other hand, contemporary feed-back process in development is just paperwork and rarely put into practice. So, the suggested feed-forward method is important to improve the connections between humanity and nature in order to regenerate the place in the longterm period.

\section{Conclusion and continuation of regenerative design in urban design}

This research by design project has explored the development of sustainable design towards an evolutionary transition where human actors participate in a co-evolutionary way with nature to sustain the whole living system.

In the literature review the main sustainability approaches that are currently dominant in design and urban practice were explored and how each has reached an evolutionary cul-de-sac due to their nostalgic, artificial models and the inability to fully escape mechanistic thinking. Meanwhile, ideas, methods and techniques from ecology were identified and further developed to have the characteristics of a regenerative design process. The contemporary green or ecological approaches only include half of the solution of urban sustainability. They lack the natural integration of human activities and needs with the natural living system with the objective of improving the natural system while benefitting humankind. It then centralised into the regenerative design process by further investigating and improving systemic understanding of human needs and the natural living system. The review concluded that the regenerative design process, with its restorative and coevolutionary rules, can evolve to sustain the whole living system.

The human, cultural and governance elements of urban habitat such as, buildings, materials, high population growth, urban management, etc., create challenges to reach towards the pure regenerative urban design.

With that, the regenerative design process articulates, which of method, technology, design is appropriate to which places (story of the sense of a place) and in which time (short and long term) with what kind of people for what yield within the frame of co evolution of the whole system. The whole research shows clearly that the solution for urban sustainability is not a static or specific set of strategies but the urban sustainability is the application of right choice of tools with the main objective of human participation of the process of evolving natural living system.

Finally, regenerative design practice improves and makes efficient the whole living system. It further enriches local economic, social, political capital as well as environment factors in the short term which would eventually lead in the long term to national active participation. The gigantic character of regenerative design is natural thinking to create natural solutions and life organisation, addressing every needed factor to make a place more sustainable.

To apply regenerative design urban planners or urban designers, in sustainable urban practice, should redefine their role while redefining the design process.

In redefining the role and process of urban design, the research suggests the following further investigations to improve it. The urban designers/planners need to capitalise and commit a reasonable time to study the place, ideally while living there to experience the full nature of the place. Secondly, they should shift from utopian urban design culture to pragmatic thinking of regenerative sustainability by centralising the life supportive practice which could heal the environment whilst going beyond the typical strategic design thinking. The urban planner/designer's role should continue with short and long-term management plans in order to coevolve the regenerative life pattern by changing 
attitudes along with physical design process (Ratnayake $\&$ Butt, 2018). Therefore, the urban designer has a dual role in regenerative sustainable development paradigm, designing physical plans and entering into the management of place in both the short and long-term direction with the objective of a participating human in the natural co evolution of the whole system.

The ambition of this paper was to introduce the idea and concept of regenerative design as multidrive approach from various disciplines - socioecological systems, social metabolism, urbanism, evolution theory, biology, etc., to contribute to a better understanding of what this 'co-evolutionary in sustainability' might mean in the context of the built environment generally. Similarly, these findings provide an important lesson to policymakers who seek to use the sustainability applications in urban design and how it is important to activate the urban system.

\section{Notes}

Place $=$ Core identity of the relationships of human systems, other biotic systems, earth systems, and the consciousness / spirit that connects them. ${ }^{\circledR R}$ Regenesis

\section{References}

Beatley, T. (2004) 'Planning for sustainability in European cities: A review of practices in leading cities (2003).' In Wheeler, S. M. \& Beatley, T. (Eds.), The Sustainable Urban Development Reader. London and New York: Routledge.

Birkeland, J. (2002). Design for Sustainability. London: Routledge.

Butt, A., Ratnayake, R., \& Budge, T. (2016). Planning education and inter-cultural collaboration: awareness, innovation, reflection and preparation for practice. Bhumi, The Planning Research Journal, 3(1).

Cole, Raymond \& Oliver, Amy \& Robinson, John. (2013). Regenerative design, socio-ecological systems and coevolution. Building Research and Information. 41. 237-247. 10.1080/09613218.2013.747130.

De Silva, C. S., Warusavitharana, E. J., \& Ratnayake, R. (2017). An examination of the temporal effects of environmental cues on pedestrians' feelings of safety. Computers, Environment and Urban Systems, 64, 266-274.

Graham, P. M. (2003) Building ecology. First principles for a sustainable built environment. Oxford: Blackwell Science Ltd.

GAISMA, Accessed; July 2011. http://www.gaisma.com/en/

Mang, Pamela \& Reed, Bill. (2012). Regenerative Development regenerative development and Design. 88558879. 10.1007/978-1-4419-0851-3_303.

McDonough, W., \& Braungart, M. (2002) Cradle to Cradle - Remaking the Way We Make Things. New York: North Point Press.

McDonough, W., \& Braungart, M. (2009) Cradle to Cradle - Remaking the Way We Make Things. Vintage, London: Vintage books.

Ministry for the Environment, New Zealand. (2009) Rethinking our built environments: Towards a sustainable future, October 2009, New Zealand: Ministry for the Environment.

Ranasinghe, G., Amarawickrama, S., \& Rathnayake, R. (2016). A Study to Compare the Level of Walkability in Two Urban Neighborhoods of Sri Lanka. International Journal of Engineering Research and General Science, 4(1), 6 -13 .

Ratnayake, R., \& Butt, A. (2018). Encounters with the unfamiliar: international planning education. International Planning Studies, 23(1), 51-64.

Ratnayake, R. (2016). Fear of crime in urban settings: influence of environmental features, presence of people and social variables. Bhumi, The Planning Research Journal, 3(2).

Ratnayake, R. (2017). Sense of safety in public spaces: university student safety experiences in an Australian regional city. Rural Society, 26(1), 69-84.

Ratnayake, R. (2013). Environmental features and sense of safety. WIT Transactions on Ecology and the Environment, 179, 377-388

Reed B (2006) Shifting our mental model - "sustainability” to regeneration. Rethinking

Sustainable Construction 2006: Next Generation Green Buildings. Sarasota. 
Reed, B. (2007) Shifting from 'sustainability' to regeneration. Building Research and Information 35: 674-80.

Reed, B. (2007a) A livings systems approach to design. AIA National Convention May - Theme Keynote Address.

Ross, A. (1991). 'Is global culture warming up?' Social Text, 28 (1991): 3-30.

Salford House 4 Life, (2010) International Open Design Competition: Stage One Brief, Viewed at November 2010. http://www.salfordhouse4life.com/brief/index.html

Salford City Council, Flood Risk and New Development, Accessed; June 2011. http://services.salford.gov.uk/ solar/showmeeting.asp?ID=3390\&MGP ID=136

UNCHS (1996). An Urbanising World, Global Report on Human Settlements. Nairobi: Oxford University Press.

Walk Score, Accessed: July 2011, http:/www.walkscore.com/

WCED (World Commission on Environment and Development). (1987) Our common future. Oxford: Oxford University Press.

White arkitekter, Stockholm AB, Viewed at: July 2011, http://en.white.se/

Williams, D.E., 2007. Sustainable design: ecology, architecture, and planning. John Wiley \& Sons. 